\section{Launch of new series: bright spots, physical activity investments that work}

\author{
Emmanuel Stamatakis, ${ }^{1}$ Andrew Murray ${ }^{2}$
}

\section{BACKGROUND}

The technological, economical and labour trends that practically eliminated the need for daily physical activity in much of the developed and increasingly in the developing world occurred far too rapidly for human physiology to efficiently adapt. The result is the escalating epidemic of chronic diseases that are contributed to or amplified by physical inactivity. Re-engineering the world to help us prioritise physical activity presents many challenges. There is no single solution or 'silver bullet'. Understanding a complex problem like physical inactivity requires interdisciplinary thinking and appreciation of both the local and global context. What is clear is that tackling physical inactivity requires a multisectoral response that goes well beyond the traditional healthcare settings and involves, for example, government entities, non-governmental organisations, and private industry. Launched in 2012, the Investments that Work for Physical Activity initiative, ${ }^{1}$ builds on the 2010 Toronto Charter for Physical Activity ${ }^{2}$ and provides a superb framework for action reflecting how multifaceted our thinking should be. Of course, what works well in a specific locality under a specific set of circumstances may or may not work elsewhere in the same form, but there will always be valuable lessons to be shared.

\section{BRIGHT SPOTS: FOCUS ON SUCCESSES}

We have long focused on the problems of inactivity and the barriers we face. Change is difficult, but focusing on great ideas and what has worked has helped elite sports persons, business leaders and even politicians to lead a positive change. ${ }^{3}$ This can work to increase physical activity.

To provide a platform for sharing such lessons among practitioners, researchers and policy makers, in this issue of BJSM we

\footnotetext{
${ }^{1}$ Charles Perkins Centre, Prevention Research Collaboration, School of Public Health, University of Sydney, Sydney, Australia

${ }^{2}$ Physical Activity for Health Research Centre, University of Edinburgh, Edinburgh, UK
}

Correspondence to Dr Emmanuel Stamatakis, Charles Perkins Centre, School of Public Health, University of Sydney, Sydney 2006, Australia; emmanuel.stamatakis@sydney.edu.au launch the Bright Spots: Physical Activity Investments that Work series. Bright Spots feature physical activity-promoting initiatives from around the globe that are often innovative and creative, which could be implemented at a small scale or large scale and in a variety of contexts. If a certain programme scored an $\mathrm{A}+$, what can we learn from it?

Bright Spots will embrace complexity but will also be a platform that will highlight specific solutions that show promise. In many situations, increased physical activity may be a co-benefit of another societal trend or intervention (eg, investments on public transport systems that lead to more incidental walking). Initiatives that cross multiple sectors, domains and settings (eg, healthcare, education, exercise medicine and transportation) that have increasing physical activity as primary endpoint or as a cobenefit are particularly welcome. Researcher-led and practitioner-led programmes are equally important, as well as innovative policies and community programmes that show promise. Bright Spots will include a parallel series, the International Society of Physical Activity and Health (ISPAH) Highlights. ISPAH Highlights will share the core principles of Bright Spots but will focus more on actions that target making changes in physical activity and broader health-related outcomes at the city, regional, national or international level.

The inaugural Bright Spot featured in this issue is the embodiment of 'think global-act local' among physical activity initiatives: Agita Mundo, ${ }^{4}$ a social mobilisation network that started in Sao Paolo over 20 years ago has to date connected over 200 organisations from around the globe. We hope that Agita Mundo and all initiatives featured in forthcoming Bright Spots will educate and inspire practitioners, policy makers and researchers to work together to (re)discover the most potent medicine of all.

\section{BJSM needs you: ideas worth sharing!} Bright Spots invites submissions (http:// bjsm.bmj.com/pages/authors/\# bright spots) that target any aspect of the physical activity continuum (including exercise, sedentary behaviour, incidental physical activity, sports), supervised or unsupervised clinical exercise programmes with a strong novelty element, as well as multi-behaviour programming involving other aspects of healthy lifestyles (e.g., diet).

We welcome formal and informal evidence of the programmes' success that has or has not been published in the scientific literature. Such evidence can include longevity of the programme, rate of programme scaling up over time, or even programme growth and reach.

Study Bright Spots. What have these people done to be so successful? Can we clone/scale up successful ideas? Can we implement them where we have influence or can we further evaluate? Physical activity promotion is sparingly funded and further evaluation and discussion are warranted.

Share and support Bright Spots. BJSM readers are a powerful community and can share ideas or your take on an idea via Facebook, Twitter and other social media. Be part of the conversation at \#brightspotsBJSM.

\section{Competing interests None declared.}

Provenance and peer review Not commissioned; internally peer reviewed.

(c) Article author(s) (or their employer(s) unless otherwise stated in the text of the article) 2017. All rights reserved. No commercial use is permitted unless otherwise expressly granted.

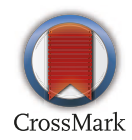

To cite Stamatakis E, Murray A. Br J Sports Med 2017;51:1388

Received 24 May 2017

Accepted 29 May 2017

Published Online First 29 June 2017

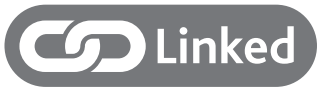

http://dx.doi.org/10.1136/bjsports-2017-098137 http://dx.doi.org/10.1136/bjsports-2016-097291

Br J Sports Med 2017;51:1388.

doi:10.1136/bjsports-2017-098096

\section{REFERENCES}

1 Investments that work for physical activity. Br J Sports Med 2012;46:709-12.

2 Global Advocacy Council for Physical Activity International Society for physical activity and Health. the Toronto Charter for physical activity: a global call for Action. J Phys Act Health 2010;7(Suppl 3):S370-85.

3 Heath C, Heath D. Switch: how to Change things when Change is hard. Broadway Books, New York, 2010.

4 Matsudo VKR, Lambert EV. Bright spots, physical activity investments that work: Agita Mundo global network. $\mathrm{Br}$ J Sports Med 2017;51:1382-3. 